\title{
2019 Spinal Cord Awards
}

(c) International Spinal Cord Society 2020

Spinal Cord is pleased to announce the winners of the 2019 paper awards:

The Best Review paper for 2019: Kwon BK, Bloom O, Wanner I-B, Curt A, Schwab JM, Fawcett J, et al. Neurochemical biomarkers in spinal cord injury. Spinal Cord. 2019;57:819-31.

The Best Original Research paper for 2019: Forslund EB, Jørgensen V, Roaldsen KS, Hultling C, Wahman K, Franzén E. Predictors of falls in persons with spinal cord injury—a prospective study using the Downton fall risk index and a single question of previous falls. Spinal Cord. 2019;57:91-9.

Readers' Choice Award for Best Review paper for 2019: Seif M, Gandini Wheeler-Kingshott, CAM, Cohen-Adad J, Flanders AE, Patrick F. Guidelines for the conduct of clinical trials in spinal cord injury: neuroimaging biomarkers. Spinal Cord. 2019;57:717-28.

Readers' Choice Award for Best Original Research paper for 2019: McDaid D, Park A-La, Gall A, Purcell M, Bacon M. Understanding and modelling the economic impact of spinal cord injuries in the United Kingdom. Spinal Cord. 2019;57:778-88.

The Best Papers are selected by the Associate Editors and the Editor-in-Chief, while the Readers' Choice Awards are determined by the number of downloads of papers in the first six months following publication. 